\title{
THE MODIFIED NORWOOD PROCEDURE FOR HYPOPLASTIC LEFT HEART SYNDROME: EARLY TO INTERMEDIATE RESULTS OF 120 PATIENTS WITH PARTICULAR REFRENCE TO AORTIC ARCH REPAIR
}

Kozo Ishino, MD

Oliver Stümper, MD

Joseph J. V. De Giovanni, FRCP

Eric D. Silove, FRCP

John G. C. Wright, FRCP

Babulal Sethia, FRCS

William J. Brawn, FRCS

Sponsor: Marc de Leval, MD
Background: Classic first-stage Norwood repair of hypoplastic left heart syndrome uses a homograft patch enlargement to obtain an unobstructed aorta and coronary arteries. Because of possible disadvantages of the homograft, such as lack of growth, degeneration and calcification, and availability, we have tried to repair the aorta without patch supplementation. Methods: Between February 1993 and September 1997, 120 patients, aged birth to 47 days (median 4 days) and weighing 1.7 to 4.4 kg (median $3.1 \mathrm{~kg}$ ), underwent first-stage palliation for hypoplastic left heart syndrome. The diameter of the ascending aorta ranged from 1.5 to $8.0 \mathrm{~mm}$ (median $3.0 \mathrm{~mm}$ ). Eight patients had an aberrant right subclavian artery arising from the descending thoracic aorta. In 95 patients (group I), all duct tissue was excised and the descending aorta was anastomosed to the aortic arch, which had been opened back into the ascending aorta. Then to this confluence was anastomosed the proximal main pulmonary artery. In the remaining 25 patients (group II), continuity of the aortic arch was maintained and the repair was performed with a Damus-Kaye-Stansel anastomosis. The size of the systemic-to-pulmonary shunt was $3 \mathrm{~mm}$ in 48 patients, $3.5 \mathrm{~mm}$ in 70 , and $4.0 \mathrm{~mm}$ in 2 . Results: Circulatory arrest time ranged from 19 to 105 minutes (median 54 minutes). A homograft patch was necessary for the arch reconstruction in 18 patients (15\%); 9 group I patients (10\%) and 9 group II (36\%) $(P=.001)$. There were 82 hospital survivors $(68 \%)$; 69 group I patients $(73 \%)$ and 13 group II $(52 \%)(P=.04), 71$ patients without a patch $(70 \%)$ and 11 with a patch $(61 \%)(P>.2)$. By multiple logistic regression, the aberrant right subclavian artery was a significant risk factor for hospital death $(P=.008)$. There were 6 late deaths. Sixteen of 71 patients $(23 \%)$ who underwent second-stage palliation had a neoaortic arch obstruction develop, with a peak gradient greater than $10 \mathrm{~mm} \mathrm{Hg}$; 14 group I patients $(23 \%)$ and 2 group II $(22 \%)(P>.2), 15$ without a patch $(23 \%)$ and 1 with a patch $(17 \%)(P>.2)$. Overall survivals were $57 \%$ at 1 year and $55 \%$ at 2 years. Conclusion: The modified Norwood procedure for first-stage palliation of hypoplastic left heart syndrome is possible in the majority of patients without the use of exogenous materials and does not result in an increased incidence of neoaortic arch obstruction. Repair of the aorta without patch supplementation may improve the potential for long-term growth of the new aorta. (J Thorac Cardiovasc Surg 1999;117:920-30)
$\mathrm{H}$ ypoplastic left heart syndrome is a spectrum of underdevelopment of the left-sided heart structures, characterized by aortic valve atresia or severe stenosis

From the Heart Unit, Birmingham Children's Hospital, Birmingham, United Kingdom.

Read at the Seventy-eighth Annual Meeting of The American Association for Thoracic Surgery, Boston, Mass, May 3-6, 1998.

Received for publication May 8, 1998; revisions requested June 10, 1998; revisions received Dec 22, 1998; accepted for publication Jan 25, 1998 with hypoplasia or absence of the left ventricle. ${ }^{1}$ Coarctation of the aorta is usually associated with the lesion $^{2}$ and may impede retrograde blood flow to a

\footnotetext{
Address for reprints: William J. Brawn, FRCS, Heart Unit, Birmingham Children's Hospital, Steelhouse Lane, Birmingham B4 6NH, United Kingdom.

Copyright (C) 1999 by Mosby, Inc.
}

$0022-5223 / 99 \$ 8.00+0 \quad \mathbf{1 2 / 6 / 9 7 3 7 3}$ 
diminutive ascending aorta. Survival after birth depends entirely on systemic blood flow through a patent ductus arteriosus and shunting at the atrial level. Without surgical treatment, practically all infants with this complex cardiac anomaly die within the first month of life. ${ }^{3,4}$

Since Norwood, Lang, and Hansen ${ }^{5}$ first reported successful application of a palliative staged approach in 1983, the outlook for the patients with hypoplastic left heart syndrome has dramatically improved.6,7 Multistaged reconstructive surgery, involving the Norwood procedure followed by bidirectional Glenn and Fontan operations, is currently the established treatment for infants with hypoplastic left heart syndrome. However, stage I palliation still remains a challenging step with a high mortality. The purpose of the initial palliation is to create an unobstructed systemic outflow tract from the right ventricle, together with placement of a systemicto-pulmonary shunt. The classic Norwood operation uses homograft augmentation of the entire aortic arch to obtain an unobstructed aorta and coronary arteries. ${ }^{8}$ Possible disadvantages of the homograft, such as lack of growth, degeneration and calcification, and availability, stimulated us to construct a neoaorta by a direct anastomosis of the main pulmonary artery to a hypoplastic ascending and transverse aorta without patch supplementation. Our initial results with developing surgical techniques to meet this objective have been reported. ${ }^{9}$ The purpose of the present study was to assess the operative and intermediate-term results of the modified Norwood procedure for the first-stage palliation of hypoplastic left heart syndrome in our first 120 infants.

\section{Patients and methods}

Patient population. Between February 1993 and September 1997, 120 consecutive infants (78 boys and 42 girls) underwent a first-stage palliation for hypoplastic left heart syndrome. Hypoplastic left heart syndrome was defined as left ventricular hypoplasia associated with mitral and aortic hypoplasia or atresia. The diagnosis was made antenatally in 24 patients. Ten were preterm infants ( $<37$ weeks' gestational age). Six patients underwent previous interventions, including balloon aortic valvotomy in 4 patients, balloon atrial septostomy in 1, and repair of coarctation of the aorta in 1 . Two patients had chromosomal abnormality: Di George syndrome and Turner syndrome.

On arrival at Birmingham Children's Hospital, all patients underwent detailed echocardiographic examination. The 120 patients fell into 4 anatomic groups. The largest group of 109 patients $(91 \%)$ had normally related great arteries, aortic atresia or stenosis, and mitral atresia or stenosis. Six patients $(5 \%)$ had double-outlet right ventricle with aortic atresia or stenosis and mitral atresia or stenosis. Two of these 6 had severe subaortic stenosis. Four patients (3\%) had complete atrioventricular septal defect with left ventricular hypoplasia and aortic stenosis. One patient (1\%) had dextro-transposition

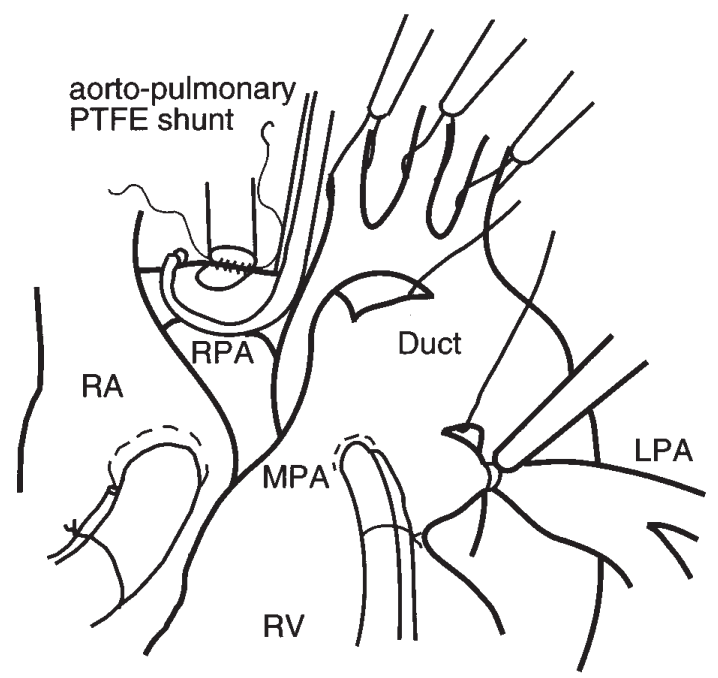

Fig 1. The cannulation technique with the arterial cannula inserted in the proximal main pulmonary artery $(M P A)$ and the venous cannula inserted in the right atrium $(R A)$. The left pulmonary artery $(L P A)$ is occluded with a tourniquet, and there are also tourniquets around the cervical vessels. A polytetrafluoroethylene (PTFE) conduit is being anastomosed to the right pulmonary artery $(R P A) . R V$, right ventricle.

of the great arteries with a hypoplastic left ventricle, multiple ventricular septal defects, and aortic and mitral stenosis. The mean diameter of the ascending aorta was $3.4 \pm 1.5 \mathrm{~mm}$ (median $=3.0 \mathrm{~mm}$, range 1.5 to $8.0 \mathrm{~mm}$ ) and was $2.0 \mathrm{~mm}$ or less in 26 patients. Associated anomalies included an aberrant right subclavian artery arising from the descending aorta in 8 patients, a left superior vena cava in 6 , and partial anomalous pulmonary venous connection in 1 . Any tricuspid or common atrioventricular valve regurgitation was graded as none, mild, moderate, or severe by color flow Doppler echocardiography: mild if the regurgitant jet was detected in less than one third of the area of the right atrium, moderate if detected in more than one third but less than two thirds, and severe if detected in more than two thirds of the right atrium. ${ }^{10}$ Twenty-five $(21 \%)$ patients had mild tricuspid or common atrioventricular valve regurgitation, $4(3 \%)$ had moderate, and $2(2 \%)$ had severe regurgitation.

The median age at operation was 4 days, range 5 hours to 47 days, including 57 patients $(48 \%)$ younger than 40 days and 6 patients $(5 \%)$ older than 4 weeks. The mean weight at operation was $3.2 \pm 0.5 \mathrm{~kg}$ (median $3.1 \mathrm{~kg}$, range 1.7 to 4.4 $\mathrm{kg}$ ), and 15 patients $(13 \%)$ weighed less than $2.5 \mathrm{~kg}$. Sixty patients $(50 \%)$ underwent mechanical ventilation before the operation, and all but 3 patients received an infusion of alprostadil (prostaglandin $\mathrm{E}_{\mathrm{l}}$ ). Forty-six patients (38\%) had moderate to high inotropic support (dobutamine $10 \mu \mathrm{g} / \mathrm{kg}$ per minute). One infant had acute renal failure necessitating preoperative peritoneal dialysis.

Operative technique. Through a midline sternotomy, the thymus gland was excised. The head vessels were exposed and looped with tourniquets in preparation for circulatory 


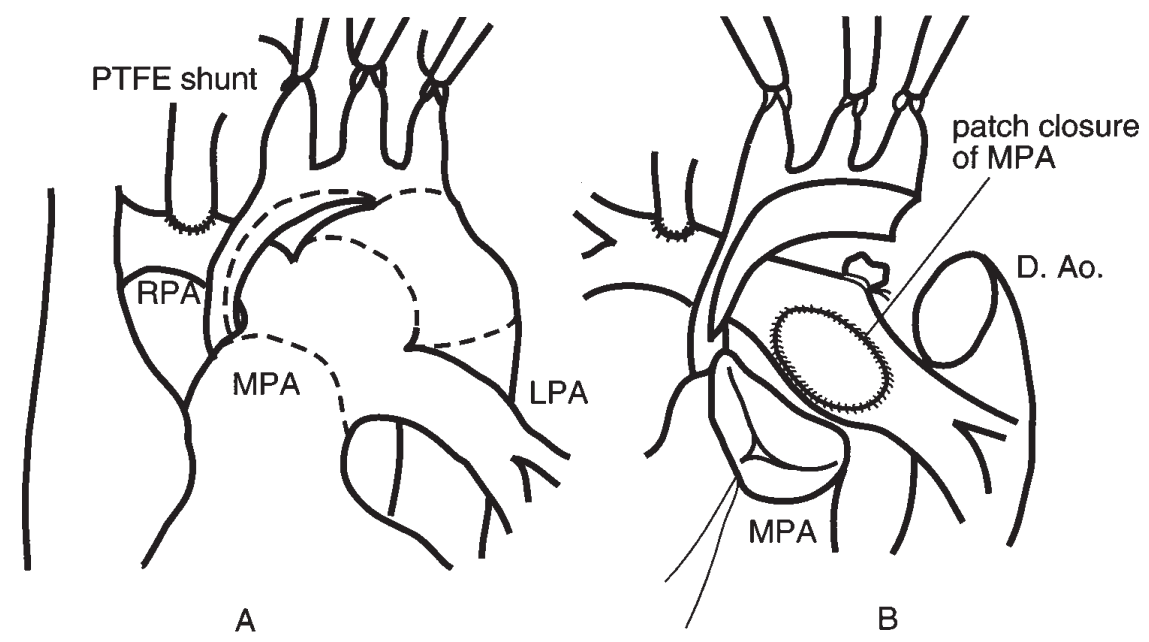

Fig 2. A, The dotted lines show the level for transection of the main pulmonary artery (MPA), ductus arteriosus, descending aorta $(D . A o)$, and distal aortic arch, and the aortotomy from the aortic arch back down into the ascending aorta. B, The main pulmonary artery is transected. The patent ductus arteriosus is ligated and transected. All duct tissue, including the segment of aorta where the coarctation is normally found, is excised. The aortic arch is opened into the ascending aorta to the level of the proximal main pulmonary artery. PTFE, Polytetrafluoroethylene; $L P A$, left pulmonary artery; $R P A$, right pulmonary artery.

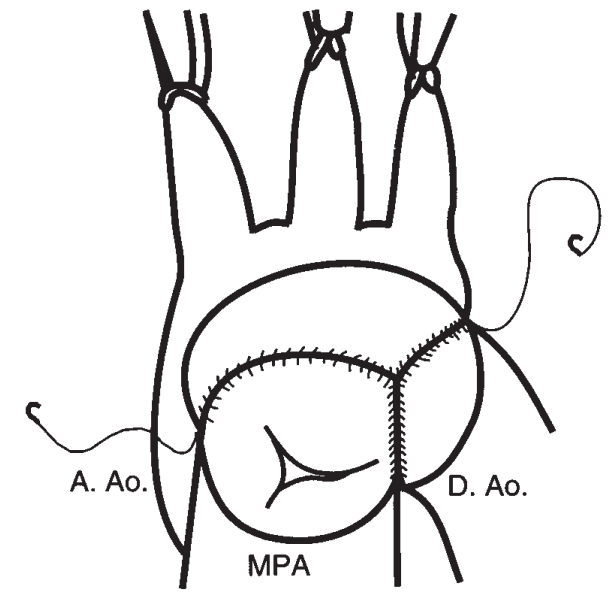

A

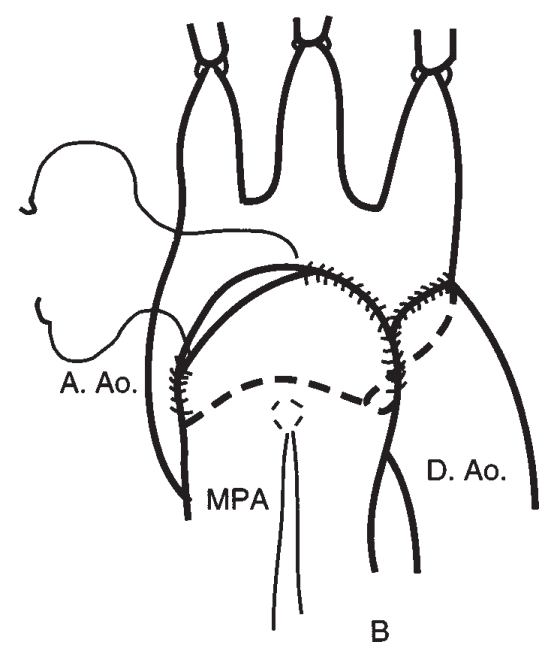

B

Fig 3. A and B, The descending aorta is anastomosed to the posterior wall of the aortic arch; then to this confluence is anastomosed the proximal main pulmonary artery. A.Ao, Ascending aorta; D.Ao, descending aorta; MPA, main pulmonary artery.

arrest. Cardiopulmonary bypass (CPB) was established by cannulation of the main pulmonary artery and the right atrial appendage. The branch right and left pulmonary arteries were immediately occluded and systemic cooling was begun. During the cooling phase, the ascending aorta was carefully mobilized and a polytetrafluoroethylene (PTFE) tube* for the

*Gore-Tex tube, registered trademark of W. L. Gore \& Associates, Inc, Flagstaff, Ariz. modified right Blalock-Taussig shunt was anastomosed to the upper border of the right pulmonary artery. At a nasopharyngeal temperature of less than $17^{\circ} \mathrm{C}$, the circulation was arrested and the head vessels were snared. Cold crystalloid cardioplegic solution $(30 \mathrm{~mL} / \mathrm{kg})$ was administered from a side port of the arterial cannula after clamping of the descending thoracic aorta. All cannulas were then removed from the heart. The main pulmonary artery was transected just proximal to the bifurcation and the distal pulmonary arteries were 
Table I. Univariable relations between categoric variables and hospital death

\begin{tabular}{|c|c|c|c|c|}
\hline \multirow[b]{2}{*}{ Factor } & \multicolumn{4}{|c|}{ Hospital death } \\
\hline & $\begin{array}{l}\text { No. of } \\
\text { patients }\end{array}$ & $\%$ & $\begin{array}{l}\text { Odds ratio } \\
(95 \% \text { CI) }\end{array}$ & $\mathrm{P}$ value \\
\hline \multicolumn{5}{|l|}{ Gender } \\
\hline Male & 78 & 32 & $1.0(0.4-2.1)$ & .902 \\
\hline Female & 42 & 31 & & \\
\hline \multicolumn{5}{|l|}{ Prematurity } \\
\hline Yes & 10 & 50 & $2.3(0.6-8.6)$ & .193 \\
\hline No & 110 & 30 & & \\
\hline \multicolumn{5}{|l|}{ Previous intervention } \\
\hline Yes & 6 & 17 & $0.4(0-3.7)$ & .418 \\
\hline No & 114 & 32 & & \\
\hline \multicolumn{5}{|l|}{ Anatomic subtype } \\
\hline $\mathrm{AA}+\mathrm{MA}$ & 49 & 38 & & .747 \\
\hline $\mathrm{AA}+\mathrm{MS}$ & 24 & 38 & & \\
\hline $\mathrm{AS}+\mathrm{MA}$ & 10 & 30 & & \\
\hline $\mathrm{AS}+\mathrm{MS}$ & 37 & 22 & & \\
\hline \multicolumn{5}{|l|}{ ARSCA } \\
\hline Yes & 8 & 88 & $18.3(2.2-154.8)$ & $<.001$ \\
\hline No & 112 & 28 & & \\
\hline \multicolumn{5}{|l|}{$\begin{array}{l}\text { Left superior vena } \\
\text { cava }\end{array}$} \\
\hline Yes & 6 & 33 & $1.1(0.2-6.2)$ & .928 \\
\hline No & 114 & 32 & & \\
\hline \multicolumn{5}{|l|}{$\begin{array}{l}\mathrm{AV} \text { valve regurgitation } \\
\text { (moderate or severe) }\end{array}$} \\
\hline Yes & 6 & 67 & $4.7(0.8-26.9)$ & .059 \\
\hline No & 114 & 30 & & \\
\hline \multicolumn{5}{|l|}{$\begin{array}{l}\text { Preop inotropic } \\
\text { support (moderate } \\
\text { or high) }\end{array}$} \\
\hline Yes & 46 & 33 & $1.1(0.5-2.4)$ & .861 \\
\hline No & 74 & 31 & & \\
\hline \multicolumn{5}{|l|}{$\begin{array}{l}\text { Preop respiratory } \\
\text { support }\end{array}$} \\
\hline Yes & 60 & 28 & $1.4(0.6-2.9)$ & .432 \\
\hline No & 60 & 35 & & \\
\hline \multicolumn{5}{|l|}{$\begin{array}{l}\text { Earlier year of } \\
\text { operation (before } \\
1996 \text { ) }\end{array}$} \\
\hline Yes & 60 & 32 & $1.0(0.5-2.2)$ & 1.000 \\
\hline No & 60 & 32 & & \\
\hline \multicolumn{5}{|l|}{ Surgeon } \\
\hline B.S. & 29 & 41 & $1.8(0.7-4.2)$ & .197 \\
\hline W.J.B. & 91 & 29 & & \\
\hline \multicolumn{5}{|l|}{$\begin{array}{l}\text { Type of aortic arch } \\
\text { repair }\end{array}$} \\
\hline Arch continuity (+) & 25 & 48 & $2.4(1.0-6.1)$ & .048 \\
\hline Arch continuity (-) & 95 & 27 & & \\
\hline \multicolumn{5}{|l|}{$\begin{array}{l}\text { Patch supplementation } \\
\text { for arch repair }\end{array}$} \\
\hline Yes & 18 & 39 & $1.5(0.5-4.1)$ & .475 \\
\hline No & 102 & 30 & & \\
\hline \multicolumn{5}{|l|}{ Size of shunt } \\
\hline $3.5 \mathrm{~mm}$ & 70 & 34 & $1.4(0.6-3.1)$ & .407 \\
\hline $3.0 \mathrm{~mm}$ & 48 & 27 & & \\
\hline
\end{tabular}

$C I$, Confidence interval; $A A$, aortic atresia; $A S$, aortic stenosis; $M A$, mitral atresia; $M S$, mitral stenosis; $A R S C A$, aberrant right subclavian artery; $A V$, atrioventricular.

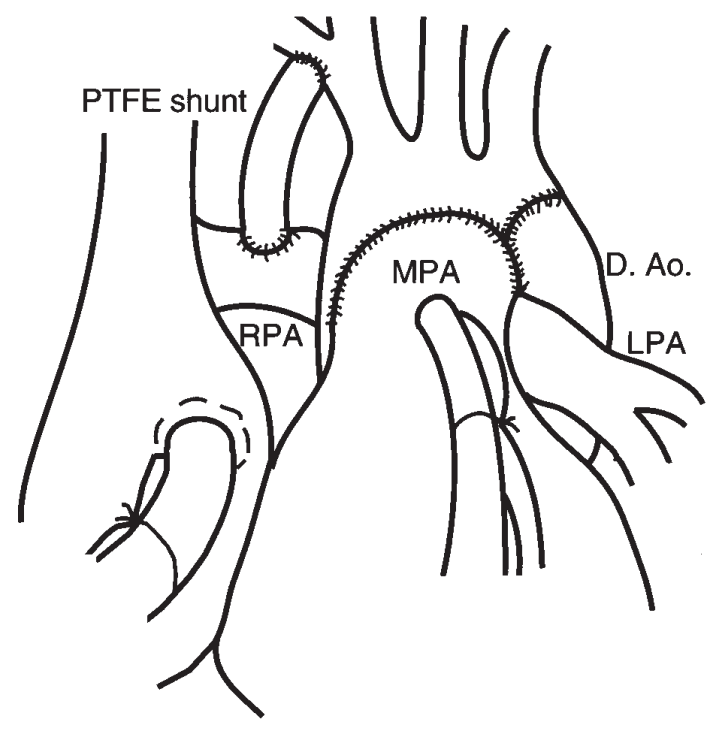

Fig 4. After atrial septectomy, the heart is recannulated and CPB is resumed. During rewarming the proximal anastomosis of the polytetrafluoroethylene shunt is placed on the innominate artery. D.Ao, Descending aorta; $M P A$, main pulmonary artery; $R P A$, right pulmonary artery; $P T F E$, polytetrafluoroethylene.

repaired with a direct suture $(\mathrm{n}=31)$, a patch of pulmonary homograft $(n=40)$, bovine pericardium $(n=37)$, or native pericardium $(\mathrm{n}=12)$. In 95 patients (group I), the descending thoracic aorta was extensively mobilized by blunt dissection, without division of intercostal arteries. All duct tissue was excised from the aorta, thus disconnecting the descending aorta from the aortic arch. The aortic arch was opened inferiorly back down into the ascending aorta to the level of the transected end of the main pulmonary artery. The back wall of the descending thoracic aorta was anastomosed to the posterior wall of the aortic arch. The proximal main pulmonary artery was anastomosed to this confluence, extending the anastomosis down to the opened out ascending aorta ${ }^{9}$ (Figs 1 to 4). Among the remaining 25 patients (group II), 14 patients had an ascending aortic diameter greater than $4.5 \mathrm{~mm}, 6$ had an aberrant right subclavian artery arising from the descending aorta, and 5 had coarctation of the transverse aortic arch. In this group, continuity of the aortic arch was maintained and the proximal main pulmonary artery was directly anastomosed to the ascending aorta and aortic arch. When undue tension of the aortic arch and its branch arteries was unavoidable, a piece of pulmonary homograft was used to supplement the arch repair in a similar fashion to the classic Norwood method. The atrial septum was excised, working through the purse-string suture on the atrial appendage. The heart was then recannulated, de-aired, clamps were removed, and the patient was rewarmed to $37^{\circ} \mathrm{C}$. During rewarming, the proximal anastomosis of the modified Blalock-Taussig shunt was placed on the innominate artery. The size of the shunt was $3.0 \mathrm{~mm}$ in 48 patients, $3.5 \mathrm{~mm}$ in 70 , and $4.0 \mathrm{~mm}$ 
Table II. Univariable relations between continuous variables and hospital death

\begin{tabular}{|c|c|c|c|c|c|c|c|}
\hline \multirow[b]{2}{*}{ Factor } & \multicolumn{3}{|c|}{ Survivors $(n=82)$} & \multicolumn{3}{|c|}{ Nonsurvivors $(n=38)$} & \multirow[b]{2}{*}{$\mathrm{P}$ value } \\
\hline & Median & Mean & Range & Median & Mean & Range & \\
\hline Age (d) & 4 & 6 & $0-41$ & 3 & 7 & $0-47$ & .388 \\
\hline Weight (kg) & 3.2 & 3.2 & $2.1-4.4$ & 3.1 & 3.1 & $1.7-4.1$ & .359 \\
\hline Ascending aortic diameter (mm) & 3.0 & 3.6 & $1.5-8.0$ & 2.5 & 3.1 & $1.5-8.0$ & .008 \\
\hline Immediate preop $\mathrm{pH}$ & 7.41 & 7.41 & $7.23-7.62$ & 7.41 & 7.40 & $7.13-7.55$ & .727 \\
\hline Circulatory arrest time (min) & 53 & 54 & 19-101 & 59 & 61 & 23-105 & .015 \\
\hline
\end{tabular}

in 2. Continuous 7-0 Prolene suture (Ethicon, Inc, Somerville, NJ) was used for all anastomoses and interrupted sutures were not used. Epicardial pacing wires were placed on the right atrium and ventricle.

Postoperative management. Delayed sternal closure was used in all patients. At the completion of the operation, the sternum was left open, a PTFE sheet was sewn to the skin edges, and dressings were applied. The sternum was closed on postoperative days 1 to 5 (median, day 2). Inotropic support was commenced at the time of weaning from $\mathrm{CPB}$. The most common inotropic agents used were dobutamine 10 $\mu \mathrm{g} / \mathrm{kg}$ per minute, dopamine $3 \mu \mathrm{g} / \mathrm{kg}$ per minute, and epinephrine $0.1 \mu \mathrm{g} / \mathrm{kg}$ per minute; occasionally calcium chloride $0.25 \mathrm{mmol} / \mathrm{h}$ was also used. Mechanical ventilation with pressure-regulated neonatal ventilators was adjusted as necessary to maintain arterial oxygen saturations of $70 \%$ to $80 \%$, ventilatory rates (minimum 14 breaths/min) and peak inspiratory pressures (minimum $16 \mathrm{~mm} \mathrm{Hg}$ ) being adjusted to maintain the arterial carbon dioxide tension between 35 and $45 \mathrm{~mm} \mathrm{Hg}$. When the pulmonary vascular resistance remained low and resultant arterial oxygen saturations were higher despite minimal ventilatory support, sodium nitroprusside was carefully used to reduce systemic vascular resistance. Inspired carbon dioxide and nitrogen were not used to manipulate the pulmonary vascular resistance in these patients. Infants with low arterial oxygen saturation $(<60 \%)$ resulting from presumed high pulmonary vascular resistance were managed with alprostadil infusion or inhaled nitric oxide, or both. Before the child left the intensive care unit, oral diuretic therapy was routinely instituted. In addition, the majority of the patients received an angiotensin-converting enzyme inhibitor for afterload reduction and were discharged from the hospital on the same medical regimen.

Late management. Elective cardiac catheterization and echocardiographic examination were performed usually within 1 to 2 weeks before the second-stage bidirectional Glenn procedure. Balloon angioplasty of neoaortic arch obstruction was considered indicated when the pressure gradient across the aortic arch was greater than $10 \mathrm{~mm} \mathrm{Hg}$. A bidirectional Glenn procedure with takedown of the PTFE shunt was performed via a midline sternotomy with $\mathrm{CPB}$ and hypothermic circulatory arrest, with revision of the neoaorta or branch pulmonary arteries as necessary.

Statistical methods. The medical records, operative reports, and echocardiographic results for all patients were reviewed. Follow-up was complete for all patients. Data were entered into a computerized database and analyzed with SPSS software (SPSS Inc, Chicago, Ill) for the Macintosh computer (Apple Computer Inc, Cupertino, Calif). Hospital deaths were considered as any deaths during the hospital stay after the modified Norwood operation, regardless of duration. The data are presented as the mean \pm the standard deviation, and proportional data are presented with their $95 \%$ confidence intervals (CI). The Mann-Whitney rank sum test was used for comparison of continuous variables in 2 groups. The significance of categoric variables was analyzed by the $\chi^{2}$ test, unless the numerator of any proportion had fewer than 5 events, in which case Fisher's exact 2-tailed $t$ test was used. To identify the independent contribution of potential risk factors for hospital mortality and for development of neoaortic arch obstruction, we entered variables significant by univariable analysis into a stepwise multiple logistic regression. The actuarial survival curve was computed by Kaplan-Meier methods.

\section{Results}

One hundred two patients (85\%) underwent the modified Norwood procedure without patch supplementation for aortic arch reconstruction. A homograft patch was necessary in 9 group I patients $(10 \%)$ and 9 group II patients $(36 \%)(P=.001)$. The mean circulatory arrest time was $57 \pm 15$ minutes (median 54 minutes, range 19 to 105 minutes) and did not differ between groups I and II ( $57 \pm 13$ vs $55 \pm 22$ minutes, $P>$.2). Additional surgical procedures at the time of the first-stage palliation included open aortic valvotomy in 2 patients, repair of partial anomalous pulmonary venous connection in 1 , and takedown of the modified Blalock-Taussig shunt because of an unbalanced pulmonary/systemic blood flow in 4.

There were 82 hospital survivors $(68 \%, 95 \% \mathrm{CI}$ : $60 \%-76 \%), 69$ group I patients (73\%) versus 13 group II patients $(52 \%)(P=.04), 71$ patients without a patch $(70 \%)$ versus 11 with a patch $(61 \%)(P>.2)$. Thirtytwo patients (84\% of the hospital deaths), including 6 patients who could not be weaned from CPB, died mainly from acute cardiopulmonary collapse within the first postoperative week. These early deaths occurred in 


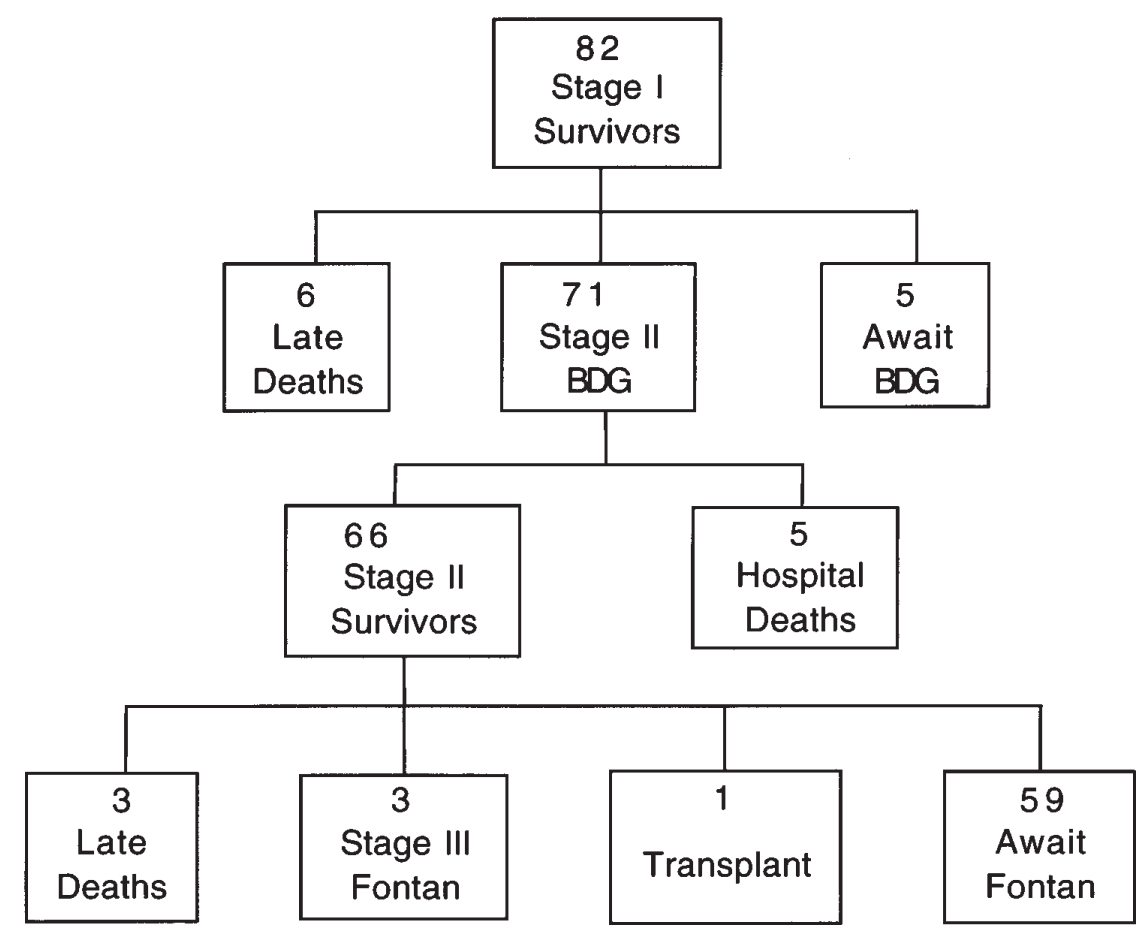

Fig 5. The current status of all hospital survivors (82/120) after stage I palliative surgery for hypoplastic left heart syndrome. $B D G$, Bidirectional Glenn procedure.

22 of 72 patients $(31 \%)$ with a 3.5 or $4.0 \mathrm{~mm}$ shunt and in 10 of the 48 patients $(21 \%)$ with a $3.0 \mathrm{~mm}$ shunt $(P>.2)$.

Eleven early reoperations were performed in 9 patients over a range of 5 to 30 days in the immediate postoperative period, including 1 repeat atrial septectomy, 2 operations for relief of a neoaortic arch obstruction, 2 shunt revisions, and 4 bidirectional Glenn shunts, which were again converted to modified Blalock-Taussig shunts in 2 patients. Among the 9 infants undergoing reoperation, there was 1 hospital death. One child who underwent a successful bidirectional Glenn shunt on day 19 after first-stage palliation is awaiting completion of the Fontan operation.

Of the variables analyzed as risk factors for hospital death, diameter of the ascending aorta, origin of an aberrant right subclavian artery from the descending aorta, type of aortic arch repair, and circulatory arrest time were significant when a univariable analysis was performed (Tables I and II). To assess the simultaneous effect of categoric and continuous variables, we graded the diameter of the ascending aorta as $2.0 \mathrm{~mm}$ or less, 2.0 to $3.0 \mathrm{~mm}, 3.0$ to $4.0 \mathrm{~mm}$, and greater than $4.0 \mathrm{~mm}$ $(P=.022, \operatorname{logistic})$. The circulatory arrest times were similarly graded by 10 -minute intervals $(P=.032$, logistic). The multivariable logistic regression analysis demonstrated a significant association between the aberrant right subclavian artery and hospital mortality $(P=.008$, odds ratio $=18.0,95 \%$ CI: $2.1-152.5)$.

Among the 82 discharged patients, there were 6 late deaths before second-stage palliation. Of the remaining 76 survivors, 71 underwent elective cardiac catheterization, echocardiographic evaluation, and subsequently second-stage palliation. Neoaortic arch obstruction (with a peak gradient greater than $10 \mathrm{~mm} \mathrm{Hg}$ ) confirmed by cardiac catheterization was present in 14 patients. Aortic arch obstruction necessitating reoperation had also developed in 2 infants, 8 and 23 days after first-stage palliation. Thus neoaortic arch obstruction developed in 16 patients $(23 \%, 95 \%$ CI: $13 \%-32 \%)$. Of these 16 patients, $14(23 \%)$ were in group I and 2 $(22 \%)$ were in group II $(P>.2) ; 15$ of them were without patch supplementation of the aortic arch and 1 had a patch $(P>.2)$. Univariable analysis did not identify any significant risk factor for the neoaortic arch obstruction. The mean peak-to-peak gradient across the aortic arch in the 16 patients was $27 \pm 6 \mathrm{~mm} \mathrm{Hg}$ (median $27 \mathrm{~mm} \mathrm{Hg}$, range 15-36 mm $\mathrm{Hg}$ ). The gradient was less than $20 \mathrm{~mm} \mathrm{Hg}$ in 3 patients, between 20 and 30 $\mathrm{mm} \mathrm{Hg}$ in 8 , and between 30 and $40 \mathrm{~mm} \mathrm{Hg}$ in 5 . Ten 


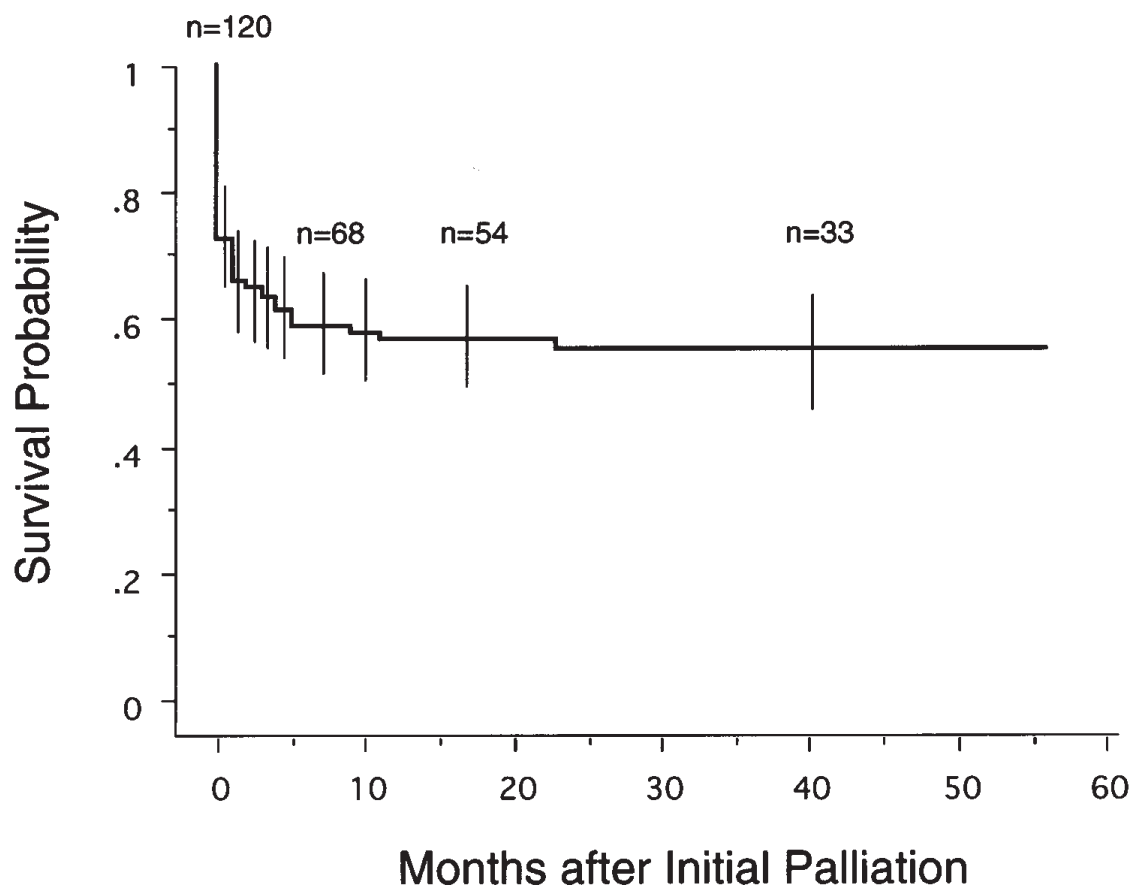

Fig 6. Actuarial survival for the entire study group of 120 patients. Vertical bars enclose a $95 \%$ confidence interval.

patients underwent successful balloon dilatation of the coarctation and 6 required surgical repair.

Postoperative tricuspid or common atrioventricular valve regurgitation assessed by echocardiography was mild in 22 patients, moderate in 3 , and severe in 1 . Forty-three of the 71 patients $(61 \%)$ had no change in the degree of tricuspid or common atrioventricular valve regurgitation, 8 (11\%) had improvement, and 20 $(28 \%)$ had deterioration when findings were compared with those of the preoperative echocardiogram. Two patients had moderate neoaortic valve regurgitation.

Seventy-one patients underwent the bidirectional Glenn shunt after a mean interval of $151 \pm 56$ days (median 140 days, range 19-415 days). There was no difference in the intraoperative interval between patients with a $3.5-\mathrm{mm}$ or $4.0-\mathrm{mm}$ shunt and those with a $3.0-\mathrm{mm}$ shunt $(155 \pm 51$ vs $145 \pm 63$ days, $P>$ .2). Concomitant procedures at stage II palliation were as follows: 12 reconstructions of the pulmonary artery, 4 repairs of the neoaortic arch obstruction, 2 atrial septectomies, 1 repair of the tricuspid valve, and 1 relief of pulmonary vein stenosis. There were 5 hospital deaths and 3 late deaths. To date, the Fontan procedure has been completed in 3 patients at the ages of $3.5,4.3$, and 3.3 years, and heart transplantation has been done in 1 patient who had severe tricuspid valve regurgitation develop after second-stage palliation.
None of these 4 patients died. The current status of all hospital survivors after the first-stage palliation is shown in Fig 5.

Actuarial survivals of the 120 patients undergoing the modified Norwood procedure were 57\% (95\% CI: $48 \%-66 \%)$ at 1 year and 55\% (95\% CI: $46 \%-64 \%)$ at 2 years (Fig 6).

\section{Discussion}

Since the introduction of staged surgical palliation for hypoplastic left heart syndrome by Norwood, Lang, and Hansen ${ }^{5}$ in 1983, most centers have adopted their method of repair. This involves extensive patch enlargement of the aorta, usually with part of a pulmonary homograft, to provide an unobstructed outflow from the right ventricle to the systemic circulation. ${ }^{8} \mathrm{We}$ were concerned that such an extensive patch placed in the aorta in the neonatal period would not be able to grow with the child and might undergo degenerative changes. In addition, any recoarctation treated by balloon dilatation could be hazardous, with the risk of rupture or false aneurysm formation. ${ }^{11}$

Interruption of the aorta can be repaired by direct anastomosis after extensive mobilization of the aortic arch vessels and descending thoracic aorta. ${ }^{12}$ It also seemed possible to extend the Damus-Kaye-Stansel connection of the pulmonary artery ${ }^{13-15}$ to the ascend- 
ing aorta into the aortic arch. A combination of these two techniques could provide a way of reconstructing the aorta without the need for patch supplementation. Additionally, all duct tissue would be removed from the anastomotic site. Use of only native tissues in the repair could be advantageous for the future growth and development of the aorta. $\mathrm{We}^{9}$ reported our initial experience with this procedure in 1995, and a similar approach was reported by Fraser and $\mathrm{Mee}^{16}$ later that year.

In this article we report the attempted application of this technique for aortic reconstruction to 120 infants and their early outcome. The hospital survival after stage I was $68 \%$ and the actuarial survival at 2 years, $55 \%$. These results are not dissimilar to other published survivals of $54 \%$ and $76 \%$ after stage I repair ${ }^{17,18}$ and actuarial survivals of $60 \%$ at 2 years in a similarly unselected group of patients. ${ }^{18}$

In $85 \%$ of cases we have been able to achieve a direct aortic anastomosis, with a recoarctation rate in the survivors of $23 \%$. All recoarctations had catheter-measured gradients of less than $40 \mathrm{~mm} \mathrm{Hg}$. Recoarctation is not an uncommon problem after this type of operation, but its true incidence is difficult to assess. Starnes and colleagues ${ }^{19}$ reported a recoarctation rate of $33 \%$ in survivors and Bartram and coworkers ${ }^{20}$ an incidence of $14 \%$ in 122 postmortem cases.

As with other centers, our management of this difficult group of patients has evolved over the review period. Initially a $3.5-\mathrm{mm}$ shunt was used, ${ }^{17,18}$ but in the later part of the series a $3.0-\mathrm{mm}$ shunt has been preferred. In our experience this has allowed for a smoother postoperative course, with fewer episodes of pulmonary overcirculation. We have not added carbon dioxide or nitrogen to the postoperative ventilatory management. Also of note, nonsurvivors in this study had a smaller ascending aorta than survivors. There were 14 deaths, comprising 54\% of 25 infants with an ascending aorta of $2.0 \mathrm{~mm}$ in diameter or less. Although this is not a universal finding, others have made this observation as well. ${ }^{21}$

The aberrant right subclavian artery arising from the descending aorta was identified as a risk factor for hospital mortality by multivariable analysis. The distal aortic arch was repaired by the extended end-to-end anastomosis after ligation and division of the aberrant right subclavian artery in 2 patients, whereas continuity of the aortic arch was kept in the other 6, regardless of the existence or not of the aortic coarctation, with only 1 hospital survivor. From a surgical point of view, the aberrant right subclavian artery prevents an extensive mobilization of the descending aorta and thus makes the direct anastomosis between the main pulmonary artery and aortic arch difficult. Other aspects of management and our indications for proceeding to the stage II procedure (bidirectional Glenn) are similar to those of other centers. ${ }^{18}$

Although in $85 \%$ of cases we have considered it possible to perform a direct aortic anastomosis, our indications for patch supplementation have become clearer. A very long, diminutive ascending aorta $(2.0 \mathrm{~mm}$ in diameter or less), ductus tissue in the aortic arch with coarctation between the left carotid artery and left subclavian artery, a long ductus arteriosus with a short descending thoracic aorta, and an aberrant right subclavian artery are contradictions to this modified repair.

Accurate analysis of the data is difficult because we cannot provide unbiased patient selection to the two types of repair. Each surgeon (W.J.B. and B.S.) made his own assessment of the anatomy and hence the surgical approach. This assessment changed over the review period according to experience with the earlier patients.

The small number of patients undergoing the Fontan procedure during the review period reflects our institution's general preference for performing the Fontan procedure in children older than 3 years of age.

Narrowing of the central pulmonary arteries did occur in this series, but the incidence and cause have yet to be analyzed.

In addition, we have not yet been able to analyze the patients who have died and to fully evaluate their aortic arch reconstruction. Our impression from echocardiographic data, their clinical evaluation, and from the postmortem results so far seen is that the arch repair has not been any greater problem in those who died.

In conclusion, in the majority of patients $(>80 \%)$ with hypoplastic left heart syndrome it is possible to perform a modified repair of the aorta without patch supplementation. Hospital survival after stage I repair and actuarial survival at 2 years are similar to those of patients undergoing a more classic repair.

We gratefully acknowledge the medical and nursing staff of the Intensive Care Unit and Cardiac wards of Birmingham Children's Hospital NHS Trust, without whose tremendous support this work would not have been possible. We thank Professor Shohei Kira, Okayama University Medical School, for his advice in statistical analysis. Figs 1 to 4 were drawn by Laszlo Kiraly, MD.

\section{REFERENCES}

1. Noonan JA, Nadas AS. The hypoplastic left heart syndrome: an analysis of 101 cases. Pediatr Clin North Am 1958;5:1029-56.

2. Von Rueden TJ, Knight L, Moller JH, Edwards JE. Coarctation of the aorta associated with aortic valvular atresia. Circulation $1975 ; 52: 951-4$. 
3. Sinha SN, Rusnak SL, Sommers HM, Cole RB, Muster AJ, Paul $\mathrm{MH}$. Hypoplastic left ventricle syndrome: analysis of thirty autopsy cases in infants with surgical considerations. Am J Cardiol 1968;21:166-73.

4. Hawkins JA, Doty DB. Aortic atresia: morphologic characteristics affecting survival and operative palliation. J Thorac Cardiovasc Surg 1984;88:620-6.

5. Norwood WI, Lang P, Hansen DD. Physiologic repair of aortic atresia-hypoplastic left heart syndrome. N Engl J Med 1983;308: 23-6.

6. Murdison KA, Baffa JM, Farrell PE Jr, et al. Hypoplastic left heart syndrome: outcome after initial reconstruction and before modified Fontan procedure. Circulation 1990;82(Suppl):IV199-207.

7. Iannettoni MD, Bove EL, Mosca RS, et al. Improving results with first-stage palliation for hypoplastic left heart syndrome. J Thorac Cardiovasc Surg 1994;107:934-40.

8. Pigott JD, Murphy JD, Barber G, Norwood WI. Palliative reconstructive surgery for hypoplastic left heart syndrome. Ann Thorac Surgery 1988;45:122-8.

9. Bu'Lock FA, Stümper O, Jagtap R, et al. Surgery for infants with a hypoplastic systemic ventricle and severe outflow obstruction: early results with a modified Norwood procedure. Br Heart $\mathbf{J}$ 1995;73:456-61.

10. Stevenson JG. Two-dimensional colour Doppler estimation of the severity of atrioventricular valve regurgitation: important effects of instrument gain setting, pulse repetition frequency, and carrier frequency. J Am Soc Echo 1989;2:1-10.

11. Hellenbrand WE, Allen HD, Golinko RJ, Hagler DJ, Lutin W, Kan J. Balloon angioplasty for aortic recoarctation: results of Valvuloplasty and Angioplasty of Congenital Anomalies registry. Am J Cardiol 1990;65:793-7.

12. Norwood WI, Lang P, Castaneda AR, et al. Reparative operations for interrupted aortic arch with ventricular septal defect. J Thorac Cardiovasc Surg 1983;86:832-7.

13. Damus R. Correspondence. Am Thorac Surg 1975;20:724.

14. Kaye MP. Anatomic correction of transposition of the great arteries. Mayo Clin Proc 1975;50:638-40.

15. Stansel HC. A new operation for D-loop transposition of the great vessels. Ann Thorac Surg 1975;19:565-7.

16. Fraser CD Jr, Mee RBB. Modified Norwood procedure for hypoplastic left heart syndrome. Ann Thorac Surg 1995;60 (suppl):S546-9.

17. Forbess JM, Cook N, Roth SJ, Serraf A, Mayer JE Jr, Jonas RA. Ten-year institutional experience with palliative surgery for hypoplastic left heart syndrome: risk factors related to stage I mortality. Circulation 1995;92 (Suppl):II262-6.

18. Bove EL, Lloyd TR. Staged reconstruction for hypoplastic left heart syndrome. Ann Surg 1996;224:387-95.

19. Starnes VA, Griffin ML, Pitlick PT, et al. Current approach to hypoplastic left heart syndrome: palliation, transplantation, or both? J Thorac Cardiovasc Surg 1992;104:189-95.

20. Bartram U, Grünenfelder J, Van Praagh R. Causes of death after the modified Norwood procedure: a study of 122 postmortem cases. Ann Thorac Surg 1997;64:1795-802.

21. Bando K, Turrentine MW, Sun K, et al Surgical management of hypoplastic left heart syndrome. Ann Thorac Surg 1996;62:70-7.

\section{Discussion}

Dr Roger B. B. Mee (Cleveland, Ohio). I thoroughly enjoyed becoming acquainted with the total experience of the modified Norwood stage I operation from Dr Brawn's group in Birmingham, England. Europe has generally been late in becoming involved in surgery for hypoplastic left heart syndrome, and the Birmingham experience of 120 cases dating from February 1993 to September 1997 may well be the largest experience in Europe over that period. Apart from the PTFE shunt, no supplemental patch was used in $85 \%$ of patients for aortic arch reconstruction.

At the Cleveland Clinic Foundation over a similar period, we have a significantly smaller experience of 49 patients. The reasons for using this modification of the Norwood operation were similar to those of the Birmingham group. Our experience of 49 patients does differ a little from the Birmingham experience. We have not used supplemental patches in any patients. We have avoided cutting down into the very small ascending aorta, but instead have reimplanted the proximal aorta in the pulmonary artery root. The early hospital survival has been $80 \%$, which is not much different from the Birmingham experience. We have also had the preponderance of our deaths in those patients with ascending aortas less than $2.0 \mathrm{~mm}$ in diameter. On the other hand, small patient size or the presence of an anomalous right subclavian artery arising from the descending aorta have not as yet emerged as risk factors. Perhaps of more interest is the absence of any significant recurrent arch obstruction. Our operation differs just slightly from the Birmingham one in that we do cut back the medial side of the descending aorta and anastomose the proximal main pulmonary to a combination of the descending aorta, proximal arch, and distal ascending aorta, if it is larger than $2.0 \mathrm{~mm}$ in diameter. Mild stenosis at the origin of the right or left pulmonary arteries has been moderately common but easily repaired at the time of the bidirectional cavopulmonary shunt. Of considerable concern to us with this particular operation was whether or not the left pulmonary artery would be compressed by the short neoascending aorta. In fact, we have not had any cases of left pulmonary artery compression. Dr Brawn, would you comment on whether you have seen this complication in your series? We thought that one of the potential advantages of this modification of the Norwood operation would be a shorter circulatory arrest time. The transection of the main pulmonary artery and patching of the distal end have been performed during cooling with the heart beating. In fact, our circulatory arrest time averages less than 40 minutes for patients in whom the proximal ascending aorta is reimplanted into the right anterior sinus of the pulmonary valve.

There is growing concern about the legacy of significant circulatory arrest times, particularly in patients with hypoplastic left heart syndrome. Dr Brawn, do you think that your mean circulatory arrest time of 57 minutes, with an upper time of 105 minutes, is of significant concern? Are there any ways in which you think that circulatory arrest time could be reduced using the Birmingham method?

I highly commend the Birmingham group's excellent reporting of their series and their desire to solve some of the theoretic problems of the existing Norwood operation.

Dr Brawn. I shall discuss the circulatory arrest time first 
because that is a weak point in the paper. Some of the arrest times are long, usually when the repair is difficult. We have to make sure the operation is done accurately. Some of the arrest times are cumulative, with reperfusion between episodes, but some of the arrest times are simply long.

Having said that, we are also aware that surgeons are using circulatory arrest times of similar lengths in neonates for repair of more straightforward conditions in which biventricular repair is possible. So where does one go in terms of circulatory arrest in the neonate? In the situation of the hypoplastic left heart syndrome, one has little choice unless one follows Professor Sano's suggestion of continuing to provide antegrade perfusion through the head vessels. We have not done that.

As regards left pulmonary artery stenosis, we too were concerned. I illustrated the left pulmonary artery narrowing in the presentation, because in that particular case the stenoses seemed to be related to scarring and tethering of the vessel behind the aorta rather than to any compression. We have seen severe compression in 1 particular case in which the patient also had severe tricuspid valve regurgitation and myocardial failure. That was the 1 patient who underwent transplantation in this series.

I understand your method of moving the incision further down the aorta, and I think I might very well try that. That technique would be useful to have in one's armamentarium. I would be surprised if these complex reconstructions could be performed without an incidence of recoarctation, and in the published series of hypoplastic heart repairs it is difficult to glean what the true incidence of recoarctation is.

I am concerned about the fate of the large patch in the systemic vessel as the child grows into teenage and young adult life. That may be a false concern, but it is certainly a concern. This is one of the main reasons for trying to reconstruct the systemic outflow tract without patch supplementation.

Dr Joseph J. Amato (Chicago, Ill). I congratulate you on a wonderful series and a superb modification of the Norwood technique. I learned about this long ago and I tried it several times. In 2 instances the result was severe stenosis of the left pulmonary artery, so much so that in 1 patient I had to do a second shunt on the left pulmonary artery. Have you had to do that in any of your patients, or have you modified your patch repair to relieve the stenosis of the left pulmonary artery? Perhaps you can tell us how to avoid that pitfall.

Dr Brawn. Thank you, sir. It is difficult to avoid. The sizes of the left and right pulmonary artery always seem to differ, perhaps in part because we are putting that shunt too far out to the right. It does seem to me that when we come to the second stage that there is always room to enlarge or insert the left pulmonary artery, even if it is slightly curved, into the roof of the atrium; it can be displaced. I should also add that at the time of the first-stage repair we do relieve adventitial attachment so that the left pulmonary artery can have room below the aorta.

The median age of our patients undergoing the bidirectional Glenn procedure is 4 months, and our cardiologists are asked to be very aggressive in balloon dilating that left pul- monary artery, if needed after the bidirectional Glenn shunt. Also at the time of the bidirectional Glenn shunt, we will repair any pulmonary stenosis as best we can.

Dr Thomas L. Spray (Philadelphia, Pa). One of the potential advantages of this modification of the Norwood operation is the avoidance of an incision down into the tiny ascending aorta. A study from Children's Hospital in Philadelphia by Drs Jacobs and Rychik several years ago showed that flow in the coronary arteries is primarily systolic after the Norwood operation. Then when the aortopulmonary shunt is replaced by a venous connection by the hemi-Fontan or bidirectional Glenn operation, flow in the coronary arteries occurs in diastole. In the case of a tiny ascending aorta, I wonder whether that transition from systolic to diastolic flow, in association with any minor limitation of the inflow into the common coronary, creates ischemia that could account for some of the sudden deaths after hemi-Fontan operations that often occur outside the hospital. Could you correlate your deaths out of hospital or after the hemi-Fontan or bidirectional Glenn procedure with the size of the ascending aorta?

Another question has to do with the aberrant right subclavian artery. When that anomaly is present, generally the carotid is the first aortic branch and both the carotid and the ascending aorta are smaller than usual. I noticed that the shunt sizes that you use are also relatively small. Do you modify the takeoff of the shunt or use a larger shunt, perhaps more proximally, in patients who have an aberrant right subclavian artery to be certain that you maintain adequate flow? Have you been able to identify the causes of death in those patients with aberrant right subclavian artery, since they seem to have less favorable outcomes?

Dr Brawn. You are right. The aberrant right subclavian arteries have been a big problem; most patients with this anomaly have died. We have not used a larger shunt, a 3.0$\mathrm{mm}$ rather than a $3.5-\mathrm{mm}$ shunt recently. When on the odd occasion we have used a larger shunt, we have had overflow, and it has been more of a problem than less. We have taken the view, rightly or wrongly, that if we get a problem with desaturation, it is not the shunt size but either the runoff or a technical problem; the angiogram we showed illustrates how relatively good-sized a shunt it seems to be for the size of the vessels to which it is attached.

The size of the ascending aorta is one of our big problems. Also, it is difficult to be sure that the vessels are not stenosing as the patient grows, that they are not twisting in some way, and to show anatomically that there is a good pathway into the small ascending aorta. Our angiography may be not precise enough to make those determinations, nor is our echo evaluation. Once we discharge the child to his or her home, our problem is to try to detect changes in the coronary supply, which is usually dependent on the size of the ascending aorta, and if we do detect a change to try do something about it. We have not been able to do that so far.

Dr William G. Williams (Toronto, Ontario, Canada). This is a valuable addition to the armamentarium for hypoplastic left heart syndrome. Personally I find it easier to avoid using the homograft patch, but my question relates to the few cases 
in which you have used a homograft patch. Could you enlarge on why you have to do that in some patients?

Dr Brawn. In those instances in which we have had to use a patch, we have had technical problems with kinking and/or twisting in the repair. Patching has been a secondary, "fall back" position. When we have patched with the arch in continuity, the patch has invariably been very small and has extended just onto the proximal part of the ascending aorta. Because we have cut the pulmonary artery quite long, in general we have cut back into that patch and then anastomosed up under the arch. We end up with a main reconstruction of the new systemic outflow tract being a major pulmonary artery with very little patch. Thus for various reasons we have evolved to using a small volume of patch material.

\section{Commentary}

The report by Ishino and associates describes an experience from Birmingham, England, with what the authors believe is a modification of the stage I Norwood procedure for hypoplastic left heart syndrome. The procedures were undertaken between February 1993 and September 1997 with an actuarial survival of $57 \%$ at 1 year and 55\% at 2 years. Only 3 of the original 120 patients have successfully undergone a Fontan procedure.

Although the authors are correct that the direct anastomosis technique is a modification of the technique described more recently by Norwood and as applied presently by many centers undertaking high volumes of surgery for hypoplastic left heart syndrome, in fact their technique is essentially identical to the original description of the Norwood procedure as published in The New England Journal of Medicine in January 1983. ${ }^{1}$ The reason that Norwood and others abandoned this technique was because of both early and late arch obstruction, as well as central distortion of the pulmonary arteries. The pulmonary artery problem is of course serious in a patient in whom a Fontan procedure will ultimately be performed. Central pulmonary artery stenosis is more likely to occur with this technique, because the main pulmonary artery must be divided more distally. Also, the greater tension on the arch anastomosis can lead to central pulmonary artery compression between the aortic arch and the left main bronchus. Although the central pulmonary artery area can be supplemented with a patch, as described by the authors, nevertheless this requires a greater rate of growth of the natural pulmonary artery at this site, since only part of the circumference has growth potential.
Although the early mortality described by the authors for the stage I procedure is comparable with results reported from an earlier era, some would argue that a $32 \%$ early mortality is relatively high for the era described in this report. More important, there was significant attrition between the first and second stages, which many groups have found to be due to undetected arch obstruction. The authors concede that they have not been able to identify the cause of death in these patients. Of even greater concern is the high mortality of patients undergoing the bidirectional Glenn shunt. Many centers currently describe a mortality for this procedure of less than $5 \%$, whereas the authors had 5 hospital deaths and 3 late deaths (11\%) among their 71 patients undergoing a stage II procedure. Only 3 patients have successfully undergone a Fontan procedure.

The authors have stated that their rationale for their use of the direct anastomosis technique is that an extensive homograft patch in the aorta would not grow and might undergo degenerative changes. In fact, calcific degeneration has not proved to be a problem at the centers that have used this technique for many years, although certainly a need for balloon dilation and even stenting of the arch is not uncommon. Surely the same argument could be applied to the patch plasty of the pulmonary arteries that the authors have had to use. However, balloon dilation of the aortic arch is easier and more likely to be successful than balloon dilation of the central pulmonary arteries in the patient who has had a Norwood operation.

In summary, this is an interesting series of patients with hypoplastic left heart syndrome palliated with the original stage I Norwood technique. It will be important for the authors to report the results of Fontan procedures in this group of patients, because the ultimate goal of any stage I procedure is not just to achieve a stage I survivor, but also to achieve a low-risk Fontan candidate and subsequent survivor of the Fontan operation, who has excellent anatomy and hemodynamics. The authors have not yet achieved this goal.

Richard A. Jonas, MD Boston, Mass

\section{REFERENCE}

1. Norwood WI, Lang P, Hansen DD. Physiologic repair of aortic atresia-hypoplastic left heart syndrome. N Engl J Med 1983;308:23-5.

12/1/98075 